\title{
Is Hypoesthesia in Mental and Incisive Nerves Areas A Complication of Inferior Alveolar Nerve Block or/and Wisdom Tooth Odontectomy?
}

\author{
Ilea Aranka1, Mirică Ioana Codruța ${ }^{1 *}$, Boșca Adina Bianca ${ }^{2}$, Buhățel Dan ${ }^{1}$, Ionel Anca ${ }^{1}$, Băbțan Anida Maria ${ }^{1}$, \\ Petrescu Nausica Bianca ${ }^{1}$, Ștefănescu Teodora ${ }^{3}$, Câmpian Radu Septimiu ${ }^{1}$ and Bordea Ioana Roxana ${ }^{1}$ \\ ${ }^{1}$ Department of Oral Rehabilitation, Iuliu Hațieganu University of Medicine and Pharmacy, Romania \\ ${ }^{2}$ Department of Histology, Iuliu Hațieganu University of Medicine and Pharmacy Cluj Napoca, Romania \\ ${ }^{3}$ Medical College of Oradea University, Romania
}

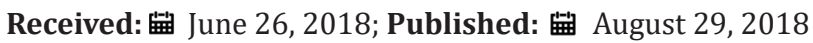

*Corresponding author: Ioana Codruța Mirică, Department of Oral Rehabilitation, Oral Health and Dental Office Management," Iuliu Hațieganu" University of Medicine and Pharmacy, Cluj-Napoca, Romania

\begin{abstract}
Introduction: Local administration of anesthetics drugs for inferior alveolar nerve (IAN) blocking and odontectomy of the inferior third molar could be associated with complications such as hypoesthesia in the territory innervated by the IAN. The purpose of this study was to investigate the possible cause of hypoesthesia occurred at the distal terminal branches of the inferior alveolar nerve, which are distant from the site of intervention. Moreover, the efficacy of low-level laser therapy (LLLT) was assessed as therapeutic approach for this type of IAN injury.
\end{abstract}

Materials and Methods: A 28-year-old patient underwent wisdom tooth odontectomy, under local anesthesia, with Articaine 4\%. The surgery took place without complications, but 7 days later, the patient complained about the sensation impairment in the distal territory of the IAN. The condition was evaluated with the visual analogue scale (VAS) and treated with B group vitamins for the neurotrophic effect and LLLT.

Results: After 10 LLLT sessions, the condition improved, with 99\% recovery of the sensitivity. This case report suggested that LLLT could be effective in the sensation impairment of IAN induced by the local administration of anesthetic substances in large amount and high concentration, associated with a vasoconstrictor.

Conclusion: Regardless of the cause of hypoesthesia (neurotoxicity of the anesthetic drug, vasoconstrictor effect or minimal local surgical trauma), restitutio ad integrum can be obtained using LLLT.

Abbreviations: IAN: Inferior Alveolar Nerve; LA- local Anesthetic; LLLT- Low Level Laser Therapy

\section{Introduction}

One of the serious complications associated with the inferior wisdom teeth removal is the injury to the inferior alveolar nerve (IAN), and the subsequent sensation impairment in the area corresponding to the terminal branches of the nerve. Some authors report that the IAN injury during surgery occurred in 0.5 up to $8.4 \%$ of cases [1-3]. The sensation impairments are usually temporary; only in less than $1 \%$ cases these changes may be permanent [4]. Rarely, taste disturbance could occur after local IAN anesthesia, because of the local anesthetic (LA) on the chorda tympani nerve [5, 6]. Haas DA et al. [7] reported that nerve injury can also occur after nonsurgical procedures [7]. The cause is not known, but it can be one or a combination of several factors, including: the traumatic injury to the nerve by direct puncture with the needle, hemorrhage in the nerve sheath, hydrostatic pressure during injection, potential neurotoxic effect of LA itself [8] or a hematoma pressuring on the IAN [9]. The permanent IAN injury caused by LA injection was reported in 0.0001 to $0.01 \%$ cases, and was the second most frequent cause, after the removal of the third molar [10].

The peripheral nerve sensory impairments are likely to be persistent when the following conditions are associated: the injury is severe, the patient is older, the therapy is delayed, and the injury is closer to the nerve cell body [11]. The symptoms induced by IAN injuries can be interpreted as hypoesthesia or paresthesia. Hypoesthesia is a decrease in normal sensation. Paresthesia is defined as any abnormal sensation such as: tingling, burning pricking, or numbness; it could be accompanied by the loss of normal sensation and often confused with hypoesthesia [12]. The hypoestezia is one of the complications of the LA. A study on 
several commercial LA (lidocaine 2\%, mepivacaine $2 \%$ and $3 \%$, prilocaine $3 \%$, and articaine $4 \%$ available in cartridges), found that articaine $4 \%$ is more prone to induce nerve injury, than the others [13]. The results of the study concluded that the injury was caused by neurotoxic effect of the LA rather than by needle penetration [13]. The study conducted by Garisto et al. [14] in the United States concluded that paresthesia subsequent LA injection alone is an uncommon event. The use of LA in high concentration, such as articaine or prilocaine $4 \%$ is more likely to induce paresthesia than lower concentration [14]. These data were consistent with reports from other countries, such as Canada [14].

Theneurotoxicityseems to be influenced by the LAconcentration and the period of nerve exposure to the LA. Concomitant neurve trauma, ischemia or both, could potentiate the LA neurotoxic effect [15]. After nerve damage, a series of pathophysiological events occurrs. The nerve degeneration begins distal to the injured site (distal stump) by Wallerian degeneration [16]; the changes proximal to the affected site (proximal stump) involve retrograde degeneration [17]. The first signs of degeneration appear in the first 24 hours after nerve injury and continue during the next 1-2 weeks by proximo-distal progression [18]. The first stage in nerve regeneration involves the macrophages and monocytes which migrate to the injury site and phagocytose the nerve stumps: the remnants of the axon and myelin, together with the Schwann cells [19]. The Schwann cells also synthesize high levels of various growth factors [20,21] and proliferate to profile the bands of Bungner [19], thus playing an important role in nerve regeneration after the injury. In response to nerve injury, Schwann cells undergo rapid changes in their phenotype and their basal lamina provides extracellular matrix for axon re-growth, a crucial process in nerve regeneration. The regeneration begins at the proximal stump and continues to the distal stump $[19,22]$. New axonal sprout grows from the nodes of Ranvier and undergo remyelination by the Schwann cells. The regenerating axons grow until reaching their synaptic target to obtain functional reinnervation [19].

The neurosensory impairment of peripheral innervation is a serious condition, not always easy to resolve. Therapeutic approaches are based on systemic administration of neurotrophic medication, local electrical stimulation, nerve repair surgery, the low-level laser therapy (LLLT) and physiotherapy [23]. Depending on the wavelength, dose, and condition of the target area, the LLLT could induce various biological responses, including: acceleration of tissue healing, moderation of inflammatory responses, improved bone repair, analgesia, reduction of swelling, restoration of normal nerve function and regulation of the immune response [23,24]. The LLLT is a bio modulatory therapy indicated for pain reduction and tissue repair. After the LLLT irradiation at the nerve injury site, improvement of the sensory has been reported [25].

\section{Case Report}

A 28-year-old patient was referred to the Department of Oral Rehabilitation, Oral Health and Dental Office Management, in March 2018, for partial inclusion of the right lower third molar (4.8) presented in Figure 1. The tooth was removed under local anesthesia. Three anesthesia carpets of Articaine $4 \%$ with epinephrine 1:100000 were locally administered. Incision of the vestibular mucosa in bayonet was performed and a trapezoidal mucoperiosteal flap was raised. The vestibular cortical bone $(2 \mathrm{~mm}$ in the apical direction) was removed under continuous cooling with a $3 \mathrm{~mm}$ diameter globular steel bur. The tooth luxation was initiated using curved paired elevators and then continued by vestibulooral movements using a lower third molar clamp until complete extraction. Then, remaining dental follicle was removed from the alveolar socket and suture in separate points with 4-0 nonabsorbable silk was performed. No complications occured during surgery. Antibiotic (Amoxicillin $2 \mathrm{~g}$ /day) and anti-inflammatory (Celecoxib $200 \mathrm{mg} /$ day) drugs were prescribed for the following five days. On the second day after surgery, the patient had fever $\left(38.5^{\circ} \mathrm{C}\right)$ and mouth opening limitation to $2-3 \mathrm{~cm}$.



After 7 days, the sutures were removed, and the patient complained about not feeling properly the teeth on the right lower arch; he had hypoesthesia in the IAN, more obvious on the right half of the lower lip. The skin hypoesthesia extended from the median line to a line corresponding to the distal surface of the first left lower premolar. The hypoesthesia in the right menton mandible region was tested by gently touching the skin with a cotton thread. The patient, keeping his eyes closed, was asked how many times he felt the touching in the right and left menton region and in the adjacent regions. He was also asked to indicate the intensity of tactile sensitivity in the right menton region compared with the left one. The patient quantified the degree of sensory dysfunction on the right menton and incisive-premolar region compared with the left one using a VAS (visual analogue scale) scale. The delimitation of the hypoesthesia area in the right menton region was also recorded.

The surgeon recommended neurotrophic medication: group B vitamins (Milgamma $100 \mathrm{mg}$ ) for three weeks, three times per day. After treatment, the patient felt a slight improvement. After that, ten laser sessions were indicated using a semiconductor laser model BTL-10 (Beautyline, Ltd, Prague, Czech Republic) with a wavelength of $830 \mathrm{~nm}$ and a hand piece with convergent emission of radiation. The energy density was $5 \mathrm{~J} / \mathrm{cm}^{2}$, at a frequency of $10 \mathrm{~Hz}$ and $50 \mathrm{~mW}$, for 50 seconds. Two sessions per week were performed. 


\section{Results}

On a VAS (Visual Analogue Scale), the quantification of the hypoesthesia intensity started at value of 7 in menton area and of 8 in the incisive-premolar region, as presented in Figure 2. Initially, the area of impaired sensitivity was extensive; after treatment, this area decreased in cranial direction, as featured in Figure 3.

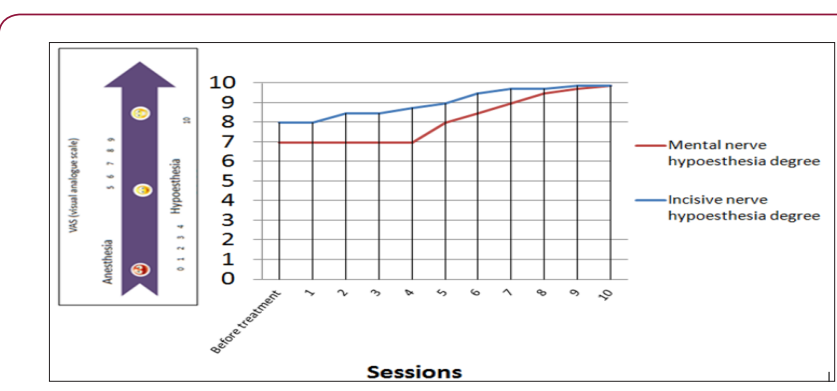

Figure 2: The Visual Analogue Scale recording.

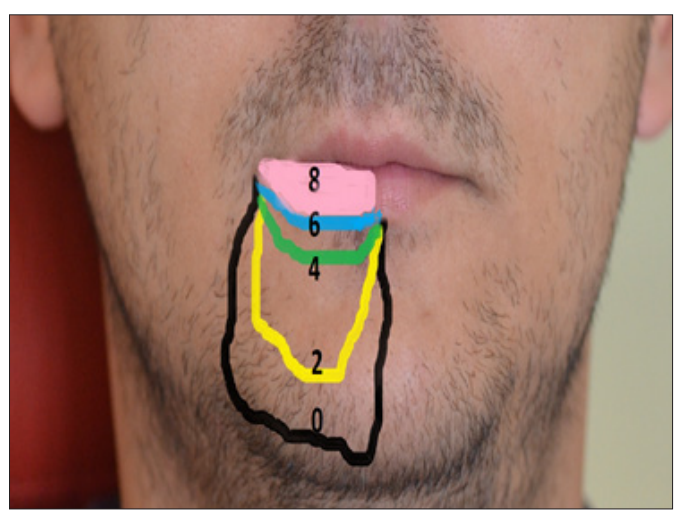

Figure 3: The follow up of the hypoesthesia area remission after LLLT Black - before treatment; Yellow -after the second session; Green - after the fourth session; Blue - after the sixth session; Pink - after the eighth session.

\section{Discussion}

The results of this case report were similar with data from the literature. For the right inferior wisdom tooth removal, 3 cartages of articain 4\% were used. Several studies [13-15] reported that articain in high quantity and concentration can induce damage to the nerve like injury during surgery. Most likely, the impaired sensation was due to the LA toxicity $[8,10,13]$, then to the surgery [26], since the tooth removal presented no complications, according to the criteria from the study of Sigron's et al. [26]. In the present case, the nerve injury could have been induced either by the cytotoxicity of the anesthetic substance and/or the effect of the associated vasoconstrictor. Interestingly, although the nerve injury was at the mandibular foramen (Spix spine) and the surgical trauma was in the posterior molar region, the hypoesthesia was reported at $6 \mathrm{~cm}$ from the intervention site. The explanation could be the effect of epinephrine hydrochloride which induced the vasoconstriction of vasa nervorum.

Since the IAN branches (the distal branches such as mental nerve and incisive nerve) are smaller in diameter, the vasa nervorum are more susceptible to subacute ischemia. Less plausible would be the compression mechanism of the vasa nervorum due to the high pressure of the anesthetic at the injection site. The injured peripheral nerves are capable of regeneration on their own due to the activation of their intrinsic growth capacity [27]. This repairing process does not implicate mitosis or cellular proliferation as in other areas of the human body [28]. Therefore, the recovery of the nerve function after peripheral nerve injury requires special conditions, including multinutrient treatment such as the vitamin B complex (vitamin $B_{1}$, vitamin $B_{6}$ and vitamin $B_{12}$ ).

The vitamin B complex administration was proved to increase the myelinated nerve fibers, the number of the Schwann cells and the diameter of the axons [29]. It also increases the expression of brain-derived neurotrophic factor (BDNF), which plays an important role in the regeneration and functional recovery of the peripheral nerves [30]. This process promotes the regeneration of the myelinated nerve fibers [29]. It was shown that the best results were achieved by a treatment with $B_{12} 1500 \mathrm{mcg}, B_{1} 50 \mathrm{mg}$ \& vitamin $B_{6} 5 \mathrm{mg}$ once daily for 12 weeks associated with folic acid $5 \mathrm{mg}$, biotin $5 \mathrm{mg}$, and alpha lipoic acid 200mg. The sensation impairment improved by $90 \%$ after the 12 -week treatment [31]. The use of the LLLT could modulate the inflammatory response of the injured tissues without side effects and might be an option for nerve regeneration [11,32-35]. Starting with the first LLLT session, the sensation impairment began to improve and after ten sessions the recovery reached $99 \%$.

\section{Conclusion}

This case report showed that a large amount of LA with a high concentration could induce sensation impairment in the innervation area. Moreover, the sensitivity could be improved by LLLT treatment. Therefore, laser therapy is a useful tool for any dentist and the treatment should be initiated as soon as possible for a complete healing of the nerve tissue.

\section{References}

1. Renton T, Yilmaz Z (2012) Managing iatrogenic trigeminal nerve injury: a case series and review of the literature. Int J Oral Maxillofac Surg 41(5): 629-637.

2. Akadiri OA, Fasola AO, Arotiba JT (2009) Incidence and risk factors for nerve injuries in mandibular third molar surgery. Niger J Med 18(4): 402-408.

3. Szalma J, Lempel E, Jeges S, Szabó G, Olasz L (2010) The prognostic value of panoramic radiography of inferior alveolar nerve damage aftermandibular third molar removal: retrospective study of 400 cases. Oral Surg Oral Med Oral Pathol Oral Radiol Endod 109(2): 294-302.

4. Hasegawa T, Ri S, Umeda M, Komori T (2011) Multivariate relationships among risk factors and hypoesthesia of the lower lip after extraction of the mandibular third molar. Oral Surg Oral Med Oral Pathol Oral Radiol Endod 111(6): 1-7.

5. Hotta M, Endo S, Tomita H (2002) Taste disturbance in two patients after dental anesthesia by inferior alveolar nerve block. Acta Otolaryngol Suppl 546: 94-98.

6. Paxton MC, Hadley JN, Hadley MN, Edwards RC, Harrison SJ (1994) Chorda Tympani Nerve Injury Following Inferior Alveolar Injection: A Review of Two Cases. J Am Dent Assoc 125(7): 1003-1006. 
7. Haas DA, Lennon DA (1995) 21-year retrospective study of reports of paresthesia following local anesthetic administration. J Can Dent Assoc 61(4):319-330.

8. Haas DA (1998) Localized complications from local anesthesia. J Calif Dent Assoc 26(9): 677-682.

9. Moon S, Lee SJ, Kim E, Lee CY (2012) Hypoesthesia after IAN block anesthesia with lidocaine: management of mild to moderate nerve injury. Restor Dent Endod 37(4): 232-235.

10. Hillerup S (2007) Iatrogenic injury to oral branches of the trigeminal nerve: records of 449 cases. Clin Oral Investig 11(2): 133-142.

11. Lam NP, Donoff RB, Kaban LB, Dodson TB (2003) Patient satisfaction after trigeminal nerve repair. Oral Surg Oral Med Oral Pathol Oral Radiol Endod 95(5): 538-543.

12. Lichtor T, Mullan JF (1990) A 10-year follow-up review of percutaneous microcompression of the trigeminal ganglion. J Neurosurg 72(1): 49-54.

13. Hillerup S, Jensen RH, Ersbøll BK (2011) Trigeminal nerve injury associated with injection of local anesthetics: needle lesion or neurotoxicity? J Am Dent Assoc 142(5): 531-539.

14. Garisto GA, Gaffen AS, Lawrence HP, Tenenbaum HC, Haas DA (2010) Occurrence of paresthesia after dental local anesthetic administration in the United States. J Am Dent Assoc 141(7): 836-844

15. Selander D (1993) Neurotoxicity of local anesthetics: animal data. Reg Anesth 18(6 Suppl): 461-468.

16. Freeman MR (2014) Signaling mechanisms regulating Wallerian degeneration. Curr Opin Neurobiol 27: 224-231.

17. Navarro X, Vivó M, Valero Cabré A (2007) Neural plasticity after peripheral nerve injury and regeneration. Prog Neurobiol 82(4): 163201.

18. Guertin AD, Zhang DP, Mak KS, Alberta JA, Kim HA (2005) Microanatomy of axon/glial signaling during Wallerian degeneration. J Neurosci 25(13): 3478-3487.

19. Battiston B, Papalia I, Tos P, Geuna S (2009) Chapter 1: Peripheral nerve repair and regeneration research: a historical note. Int Rev Neurobiol 87: 1-7.

20. Reichert F, Saada A, Rotshenker S (1994) Peripheral nerve injury induces Schwann cells to express two macrophage phenotypes: phagocytosis and the galactose-specific lectin MAC-2. J Neurosci 14(5 Pt 2): 3231 3245 .

21. Pfister LA, Papaloïzos M, Merkle HP, Gander B (2007) Nerve conduits and growth factor delivery in peripheral nerve repair. J Peripher Nerv Syst 12(2):65-82.

22. Gu X, Ding F, Williams DF (2014) Neural tissue engineering options for peripheral nerve regeneration. Biomaterials 35(24): 6143-6156.
23. Leung YY, Fung PP, Cheung LK (2012) Treatment modalities of neurosensory deficit after lower third molar surgery: a systematic review. J Oral Maxillofac Surg 70(4): 768-778.

24. Aras MH, Güngörmüş M (2010) Placebo-controlled randomized clinical trial of the effect two different low-level laser therapies (LLLT)intraoral and extraoral - on trismus and facial swelling following surgical extraction of the lower third molar. Lasers Med Sci 25(5): 641-645.

25. Gasperini G, de Siqueira IC, Costa LR (2014) Lower-level laser therapy improves neurosensory disorders resulting from bilateral mandibular sagittal split osteotomy: a randomized crossover clinical trial. J Craniomaxillofac Surg 42(5): 130-133.

26. Sigron GR, Pourmand PP, Mache B, Stadlinger B, Locher MC (2014) The most common complications after wisdom-tooth removal: Part 1: A retrospective study of 1,199 cases in the mandible. Swiss Dent J 124(10): 1042-1056.

27. Rishal I, Fainzilber M (2010) Retrograde signaling in axonal regeneration. Exp Neurol 223(1): 5-10.

28. Burnett MG, Zager EL (2004) Pathophysiology of peripheral nerve injury: a brief review. Neurosurg Focus 16(5): E1.

29. Lopatina T, Kalinina N, Karagyaur M, Stambolsky D, Rubina K, et al. (2011) Adipose-derived stem cells stimulate regeneration of peripheral nerves: BDNF secreted by these cells promotes nerve healing and axon growth de novo. PLoS One 6(3): 17899.

30. Sun H, Yang T, Li Q, Zhu Z, Wang L, et al., (2012) Dexamethasone and vitamin B (12) synergistically promote peripheral nerve regeneration in rats by upregulating the expression of brain-derived neurotrophic factor. Arch Med Sci 8(5): 924-930.

31. Maladkar M, Tekchandani C, Dave U (2014) Post-marketing surveillance of fixed dose combination of methylcobalamine, alpha lipoic acid, folic acid, biotin, benfotiamine \& vitamin B6-nutripathy for the management of peripheral neuropathy. J Diabetes Mellitus 4(2): 124-132.

32. Farhadi F, Eslami H, Majidi A, Fakhrzadeh V, Ghanizadeh M, et al., (2017) Evaluation of adjunctive effect of low level laser Therapy on pain, swelling and trismus aftersurgical removal of impacted lower third molar: A double blind randomized clinical trial. Laser Ther 26(3): 181187.

33. Veitz Keenan A, Keenan JR (2015) Trials needed to identify best management of iatrogenic inferior alveolar and lingual nerveinjuries. Evid Based Dent 16(1): 29.

34. Rosso MPO, Buchaim DV, Kawano N, Furlanette G, Pomini KT, et al., (2018) Photobiomodulation Therapy (PBMT) in Peripheral Nerve Regeneration: A Systematic Review. Bioengineering (Basel) 5(2): 44.

35. Guarini D, Gracia B, Ramírez Lobos V, Noguera Pantoja A, Solé Ventura $P$ (2018) Laser biophotomodulation in patients with neurosensory disturbance of the inferior alveolar nerve after sagittal split ramus osteotomy: A 2-year follow-up study. Photomed Laser Surg 36(1): 3-9.

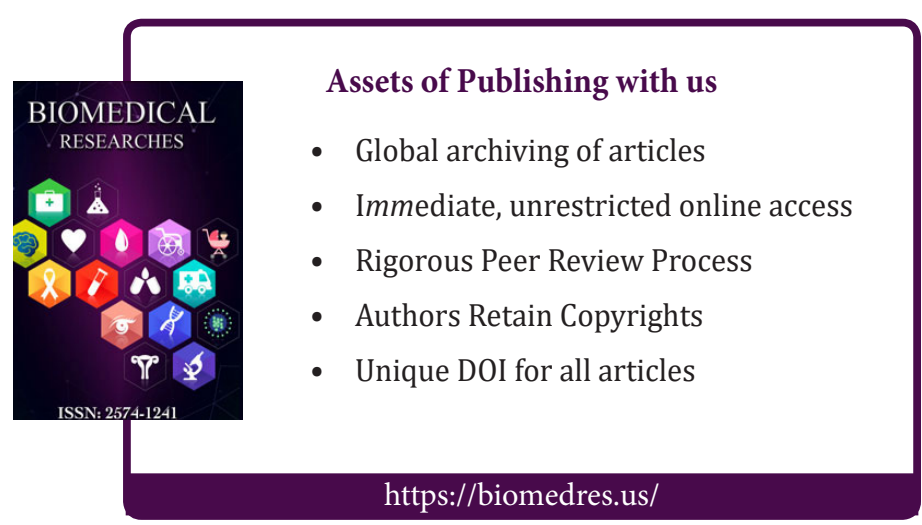

ISSN: 2574-1241

DOI: $10.26717 / B J S T R .2018 .08 .001665$

Ioana Codruța Mirică. Biomed J Sci \& Tech Res

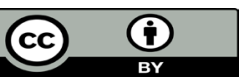

This work is licensed under Creative Commons Attribution 4.0 License

Submission Link: https://biomedres.us/submit-manuscript.php 